\title{
Model of interval multi-attribute optimization for overseas oil-gas projects
}

\author{
Yong-Zhang Huang ${ }^{1} \cdot$ Bao-Sheng Zhang ${ }^{1} \cdot$ Xin-Qiang Wei $^{2} \cdot$ Ren-Jin Sun ${ }^{1}$
}

Received: 5 March 2014/Published online: 3 April 2015

(C) The Author(s) 2015. This article is published with open access at Springerlink.com

\begin{abstract}
Because of the incompleteness and uncertainty in the information on overseas oil-gas projects, project evaluation needs models able to deal with such problems. A new model is, therefore, presented in this paper based on interval multi-attribute decision-making theory. Analysis was made on the important attributes (index) and the relationships affecting the basic factors to the project economic results were described. The interval numbers are used to describe the information on overseas oil and gas projects. On these bases, an improved TOPSIS model is introduced for the evaluation and ranking of overseas oil and gas projects. The practical application of the new model was carried out for an oil company in selecting some promising blocks from 13 oil and gas blocks in eight different countries in the Middle East. Based on these innovative studies, some conclusions are given from theoretical and application aspects. The practical application shows that the introduction of interval numbers into the evaluation and ranking of the overseas oil and gas projects can lead to more reasonable decisions. The users can do the project evaluation based on the comprehensive values as well as based on some preferred index in the project evaluation and ranking.
\end{abstract}

Bao-Sheng Zhang

bshshysh@cup.edu.cn

1 School of Business Administration, China University of Petroleum, Beijing 102249, China

2 Overseas Investment Environment Research Department, CNPC Economics and Technology Research Institute, Beijing 100724, China

Edited by Xiu-Qin Zhu
Keywords Interval data - Improved TOPSIS model · Multiple attribute decision making · Overseas oil-gas project - Alternative ranking

\section{Introduction}

Up till now, the decision-making on overseas oil and gas projects is mainly based traditional economic evaluation, usually called the net present value (NPV) method. This method can, however, work with relatively complete information and accurate data. In fact, the information about oversea oil and gas projects is often not perfect. Some indices such as geological condition parameters may be missing or the values of some index can only be estimated to an interval range. It is, therefore, not easy and nor appropriate to use the traditional NPV method in such situations. For solving this problem, the multi-attribute decision-making (MADM) theory has been put forward and applied in project evaluation research over the last 10 years. Kong (2005) has proposed a decision-making model for mineral resources by a fuzzy method using MADM theory. Liu (2007) has studied project economic evaluation using a 3-dimensionality factor, namely information, space, and reference group. Li (2004) has introduced fuzzy theory into MADM and established an economic decision model for development of mineral resources. Srdjevic et al. (2004) using the traditional TOPSIS model to solve comprehensive management problems, including economic problems and water resources. Some theoretical research work and application research have also been done in the transportation field (Janic 2003; Herrera et al. 2005).

In the oil and gas industry, similar research work has been done in geological and reservoir condition analysis 
and production prediction. Liu (2010) described a method based on MADM theory for evaluation of oil-gas reserves. In order to improve the forecast accuracy, Hou and Gui (2010) presented research work for oil production forecasting by combining the neural network technology with MADM theory. In view of the risk-benefit co-analysis, Wang et al. (2010) proposed a dynamic MAUT(Multi-Attribute Utility Theory) model for oil-gas project evaluation with respect to the three attributes, namely geological risk, market risk, and economic benefits. It can be seen that most existing research in the oil and gas industry was focused on the analysis of the geological or technical condition factors. Few reports have been found about similar research into direct consideration of the economic evaluation.

Some other MADM research work (Fan et al. 2002; Albayrak 2004; Dağdeviren 2008; Hladik 2007) have also been found. Most of this research was conducted based on point data. But the information on overseas oil-gas projects cannot, as referred above, be estimated accurate to a particular number. Only an interval can be given in practice. So, a logical approach is to introduce the interval number into the models based on the MADM theory. In this paper, the geological index and economic index are combined to build an index system expressed in interval numbers. In this way, the traditional technique for order of preference by similarity to ideal solution (TOPSIS) model is improved for overseas oil-gas project evaluation.

\section{Analysis of the factors influencing overseas oil-gas project benefits}

It is very important for decision makers to select the appropriate indices in the decision process. In this process, there are two issues worth noting, one is the type of indices, and the other is the method used to compare them. According to their nature, each index can be divided into an efficiency (positive) and cost (negative) index. For the efficiency (positive) index, such as IRR and NPV, a larger value means better. For a cost index, such as the static investment payback period (SIPP) or the total estimated investment (TEI), a smaller value means better. We may also meet another classification from the index values, namely the fixed and interval index. For fixed index, the value closer to a given fixed number suggests a better situation. By interval index, whereas all the index values falling in between a given interval can be taken as better solutions.

This paper will analyze the relationships among all the main factors affecting oil-gas project decision from two aspects, namely from the oil or gas reserve and production aspect, and from the economic value as the other aspect. For example, the reserve amount (resource scale) is affected by many geological factors, with the affecting relationships shown in Fig. 1.

As shown in Fig. 1, the factors affecting the reserve amount (resource scale) include reservoir porosity, the density of crude oil, crude oil volume factor, original oil saturation, oil (gas) layer thickness, and oil (gas) area coefficient, and they are often affected by some other factors.

Beside such important parameters as reserve amount and oil or gas production, more attention should be given to economic benefits, because the ultimate goal of a company is to make money. The factors affecting economic benefits include geological condition, market situation, engineering technology, policy and social factors, and so on. NPV is regarded as the final economic benefit index, and its relation to the other factors is shown in Fig. 2.

The NPV is calculated directly according to the project's cash input and the cash output (cash in and cash out, as shown in Fig. 2). It is also affected directly by the benchmark discount rate and contract period, which are normally taken as fixed factors. All other factors shown in Fig. 2 will affect the NPV through influencing the cash inflow and cash outflow.

\section{The index system}

Based on the research work from some scholars (e.g. Liu 2010; Wang et al. 2010, etc.) and referring to the project evaluation practices of the petroleum companies, the index system was established for this work, with the index weight expressed in interval numbers. All the indices can be classified into 3 groups.

(1) The project condition index group

The index in this group is the parameters describing the oil-gas block's basic condition information. Among these indices, the reserve scale, resource abundance and the density of crude oil are the important ones.

(2) The index related to geological conditions

The index of this group reflects some basic geological information from the oil-gas blocks, such as trap condition, hydrocarbon source rocks condition, reservoir condition. Generally, the values of these indices have strong relations to the block exploration degree. The higher the degree of exploration of the block, the more complete the information that can be obtained and the values of the index can be more accurately estimated.

(3) The economic index

The index of this group indicates what types of technology should be applied and what economic results can be obtained based on the geological situation of project. 


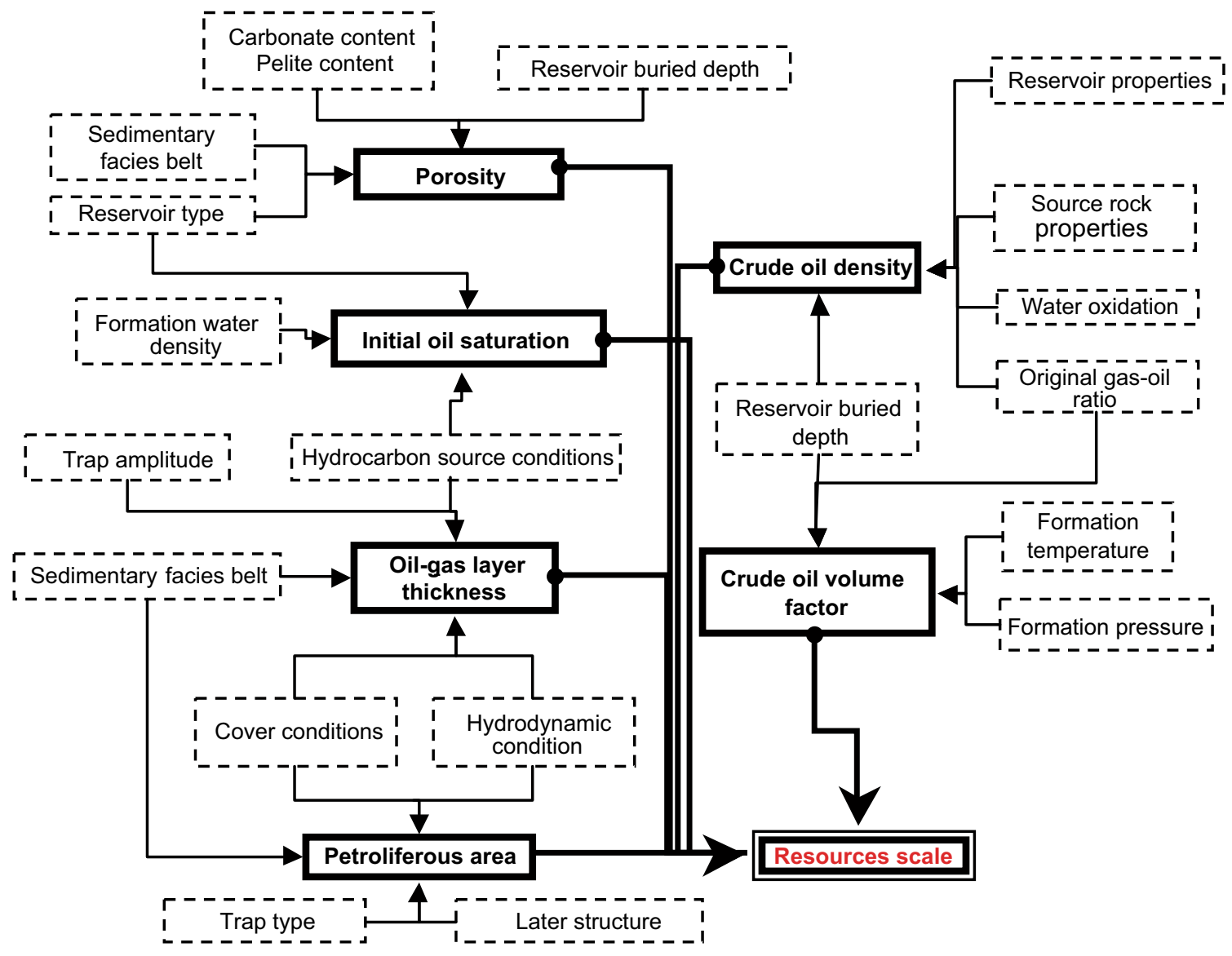

Fig. 1 The relationships among geological factors affecting the resource scale

Fig. 2 The relationships among factors affecting the economic result

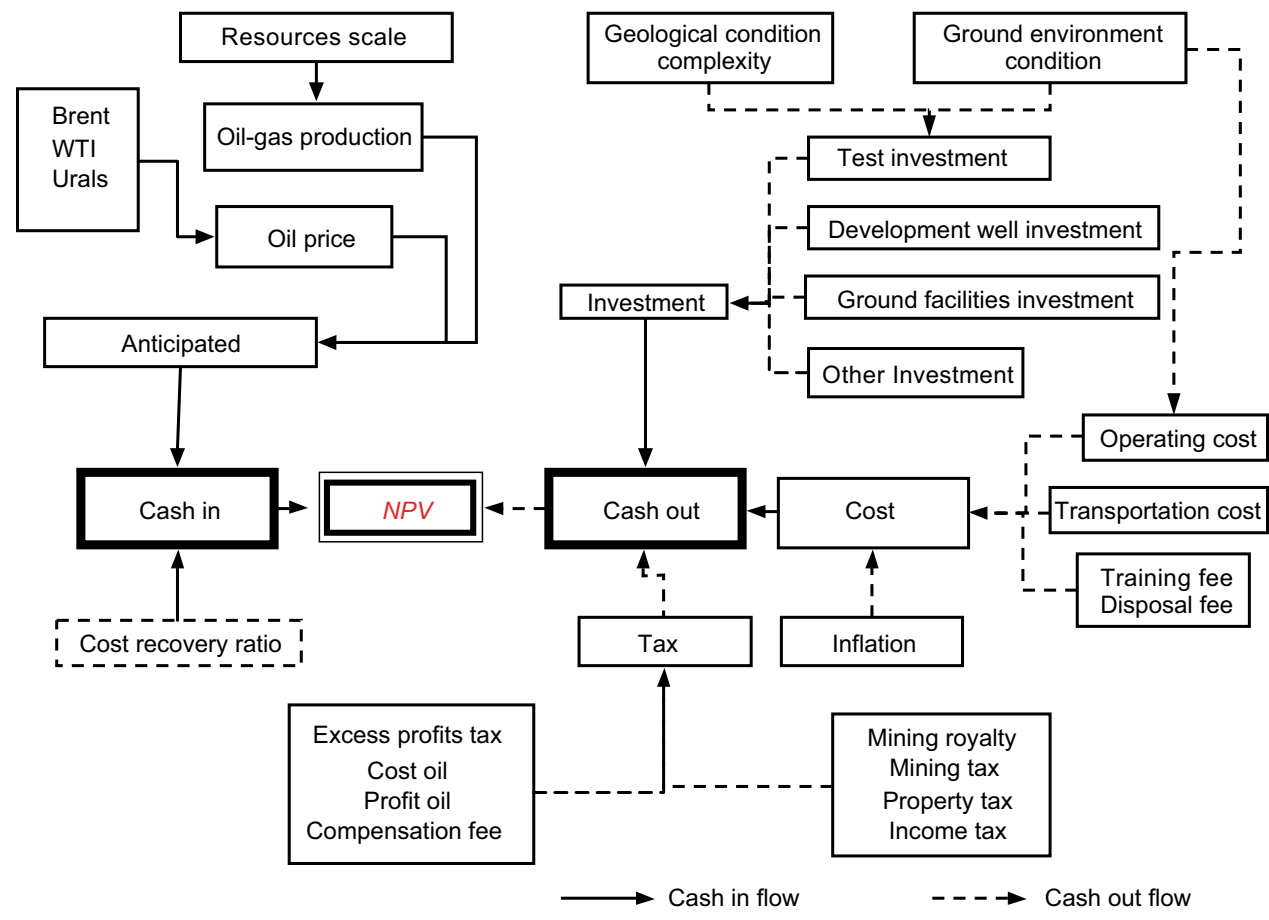


The established index system is shown in Table 1 .

The evaluation criteria should be selected for the project evaluation based on the index system. Considering that there is no uniform global standard for judging the index value, the evaluation criteria suggested in the third resource evaluation handbook published by China National Petroleum Corporation (CNPC) are applied in our research work.

\section{Method}

\subsection{Multiple attribute decision-making (MADM)}

To carry out the MADM analysis, two important things should be prepared, that is to build the set of the decision alternatives and to build the set of the attributes (index). The following expressions are generally used:

$S=\left\{S_{1}, S_{2}, \ldots, S_{m}\right\}$-set of the decision alternatives, $X=\left\{X_{1}, X_{2}, \ldots, X_{n}\right\}$-set of the attributes (index).

Meanwhile, the set $\boldsymbol{X}$ should be coupled with an index weights vector, $W=\left(W_{1}, W_{2}, \ldots, W_{n}\right)^{T}$.

In the traditional multi attribute decision process, a point number, $a_{i j}$, will be used to present the value of the alternative $i$ evaluated under the attribute $j$. A comprehensive value can be calculated for every alternative according to the set $\boldsymbol{X}$ and its coupled weight vector $\boldsymbol{W}$. The best alternative will be selected by comparison of the comprehensive values of the different alternatives.
Similar to the analysis process in the ordinary MADM process by the point data, a so called decision matrix should be also first built in this research work. The difference here in comparing to the ordinary one is that the elements of the decision matrix are all expressed in interval numbers. Generally, we use $A=\left(a_{i j}\right)_{m \times n}$ to stand for the decision matrix, where $a_{i j}=\left[a_{i j}^{\mathrm{L}}, a_{i j}^{\mathrm{U}}\right](1<i<m, 1<j<n)$,

and $a_{i j}^{\mathrm{L}}$ is the lower limit of the interval value of the alternative $i$ evaluated under the attribute $j ; a_{i j}^{\mathrm{U}}$ is the upper limit of the interval value of the alternative $i$ evaluated under the attribute $j$.

The coupled weight vector $w_{j}=\left[w_{j}^{\mathrm{L}}, w_{j}^{\mathrm{U}}\right]$ is also described with interval numbers, where $w_{j}^{\mathrm{L}}$ is the lower limit of the interval value of the weight of the attribute $j ; w_{j}^{\mathrm{U}}$ is the upper limit of the interval value of the weight of the attribute $j$.

The decision matrix of the MADM under interval data is shown in Table 2.

\subsection{The traditional TOPSIS model}

TOPSIS is a method for ranking the considered alternatives by evaluating the similarity of each alternative to the given ideal modes. Usually, two ideal modes are given, with one as the optimal mode (positive mode) and the other as worst mode (negative mode). The evaluation is
Table 1 Indices used in this work

\begin{tabular}{lllll}
\hline No. & Index & Type, unit & Attribute & Weight interval \\
\hline 1 & Reserves & Digital, $10^{4} \mathrm{t}$ & Efficiency & {$\left[w_{1}^{\mathrm{L}}, w_{1}^{\mathrm{U}}\right]$} \\
2 & Reserve abundance & Digital, $10^{4} \mathrm{t} / \mathrm{km}^{2}$ & Efficiency & {$\left[w_{2}^{\mathrm{L}}, w_{2}^{\mathrm{U}}\right]$} \\
3 & Hydrocarbon source rock thickness & Digital, $\mathrm{m}$ & Efficiency & {$\left[w_{3}^{\mathrm{L}}, w_{3}^{\mathrm{U}}\right]$} \\
4 & Lithology & Discrete & - & {$\left[w_{4}^{\mathrm{L}}, w_{4}^{\mathrm{U}}\right]$} \\
5 & Organic carbon content & Digital, $\%$ & Efficiency & {$\left[w_{5}^{\mathrm{L}}, w_{5}^{\mathrm{U}}\right]$} \\
6 & Hydrocarbon generation peak time & Discrete & - & {$\left[w_{6}^{\mathrm{L}}, w_{6}^{\mathrm{U}}\right]$} \\
7 & Trap type & Discrete & - & {$\left[w_{7}^{\mathrm{L}}, w_{7}^{\mathrm{U}}\right]$} \\
8 & Reservoir thickness & Digital, m & Efficiency & {$\left[w_{8}^{\mathrm{L}}, w_{8}^{\mathrm{U}}\right]$} \\
9 & Porosity & Digital, $\%$ & Efficiency & {$\left[w_{9}^{\mathrm{L}}, w_{9}^{\mathrm{U}}\right]$} \\
10 & Permeability & Digital, $10^{-3} \mu \mathrm{m}^{2}$ & Efficiency & {$\left[w_{10}^{\mathrm{L}}, w_{10}^{\mathrm{U}}\right]$} \\
11 & Buried depth & Digital, m & Cost & {$\left[w_{11}^{\mathrm{L}}, w_{11}^{\mathrm{U}}\right]$} \\
12 & Cover lithology & Discrete & - & {$\left[w_{12}^{\mathrm{L}}, w_{12}^{\mathrm{U}}\right]$} \\
13 & Cover layer thickness & Digital, $\mathrm{m}$ & Efficiency & {$\left[w_{13}^{\mathrm{L}}, w_{13}^{\mathrm{U}}\right]$} \\
14 & Crude oil density & Digital, g/cm & Efficiency & {$\left[w_{14}^{\mathrm{L}}, w_{14}^{\mathrm{U}}\right]$} \\
15 & Peak production & Digital, $\mathrm{t} / \mathrm{d}$ & Efficiency & {$\left[w_{15}^{\mathrm{L}}, w_{15}^{\mathrm{U}}\right]$} \\
16 & Well depth & Digital, m & Cost & {$\left[w_{16}^{\mathrm{L}}, w_{16}^{\mathrm{U}}\right]$} \\
17 & Expected investment & Digital, $10^{8} \$$ & Cost & {$\left[w_{17}^{\mathrm{L}}, w_{17}^{\mathrm{U}}\right]$} \\
18 & The total cost & Digital, $10^{8} \$$ & Cost & {$\left[w_{18}^{\mathrm{L}}, w_{18}^{\mathrm{U}}\right]$} \\
19 & Expected NPV $(10 \%)$ & Digital, $10^{8} \$$ & Efficiency & {$\left[w_{19}^{\mathrm{L}}, w_{19}^{\mathrm{U}}\right]$} \\
20 & Expected IRR & Digital, $\%$ & Efficiency & {$\left[w_{20}^{\mathrm{L}}, w_{20}^{\mathrm{U}}\right]$} \\
\hline & & & &
\end{tabular}


Table 2 Decision matrix of MADM under interval data

\begin{tabular}{lllll}
\hline Alternative set & \multicolumn{4}{l}{ Attribute set, $X$} \\
\cline { 2 - 5 } & $X_{1}$ & $X_{2}$ & & $X_{n}$ \\
\hline$S_{1}$ & {$\left[a_{11}^{\mathrm{L}}, a_{11}^{\mathrm{U}}\right]$} & {$\left[a_{12}^{\mathrm{L}}, a_{12}^{\mathrm{U}}\right]$} & $\cdots$ & {$\left[a_{1 n}^{\mathrm{L}}, a_{1 n}^{\mathrm{U}}\right]$} \\
$S_{2}$ & {$\left[a_{21}^{\mathrm{L}}, a_{21}^{\mathrm{U}}\right]$} & {$\left[a_{22}^{\mathrm{L}}, a_{22}^{\mathrm{U}}\right]$} & & {$\left[a_{2 n}^{\mathrm{L}}, a_{2 n}^{\mathrm{U}}\right]$} \\
$\vdots$ & $\vdots$ & $\vdots$ & $\cdots$ & $\vdots$ \\
$S_{m}$ & {$\left[a_{m 1}^{\mathrm{L}}, a_{m 1}^{\mathrm{U}}\right]$} & {$\left[a_{m 2}^{\mathrm{L}}, a_{m 2}^{\mathrm{U}}\right]$} & $\cdots$ & {$\left[a_{m n}^{\mathrm{L}}, a_{m n}^{\mathrm{U}}\right]$} \\
Weight vector, $\boldsymbol{W}$ & {$\left[w_{1}^{\mathrm{L}}, w_{1}^{\mathrm{U}}\right]$} & {$\left[w_{2}^{\mathrm{L}}, w_{2}^{\mathrm{U}}\right]$} & $\cdots$ & {$\left[w_{n}^{\mathrm{L}}, w_{n}^{\mathrm{U}}\right]$} \\
\hline
\end{tabular}

conducted in such a way: firstly, each alternative will be compared with the positive mode as well as with the negative mode, and on this basis, the alternative nearest to the positive mode and furthest from the negative mode will be selected as the best alternative. As for the distance in measuring the 'nearest' or 'furthest', we mean the Euclidean geometric distance. Based on the distance, a measurement called similarity degree can be calculated for each alternative in comparing its attributes to those of the positive mode and the negative mode. And then, all the alternatives can be ranked in accordance with the similarity degrees.

The decision analysis based on the traditional TOPSIS model can be carried out in accordance to the following 7 steps:

(1) Determining the values of all the alternatives under different attributes and then, buiding the initial decision matrix $A=\left(a_{i j}\right)_{m \times n}$,

(2) To turn the original decision matrix $A=\left(a_{i j}\right)_{m \times n}$ into the dimensionless matrix $R=\left(r_{i j}\right)_{m \times n}$ according to the given dimensionless principles,

(3) Building the weighted standard decision matrix $Z=$ $\left(z_{i j}\right)_{m \times n}$ (If $z_{i j}$ is not in the interval $[0,1]$, then $z_{i j}$ need to be further standardized),

(4) Giving the positive mode $U=\left(u_{1}^{+}, u_{2}^{+}, \ldots, u_{n}^{+}\right)$and the negative mode $V=\left(v_{1}^{-}, v_{2}^{-}, \ldots, v_{n}^{-}\right)$

(5) Calculating the Euclidean geometric distance of each alternative to the positive and negative modes:

$$
\begin{aligned}
d_{i}^{+} & =\sqrt{\sum_{j=1}^{n}\left(z_{i j}-u_{j}^{+}\right)^{2}}, d_{i}^{-}=\sqrt{\sum_{j=1}^{n}\left(z_{i j}-v_{j}^{-}\right)^{2}} \\
i & =1,2, \ldots, m
\end{aligned}
$$

(6) Calculating the similarity degree of each alternative to the ideal modes according to Eq. (2)

$$
C_{i}=\frac{d_{i}^{-}}{d_{i}^{+}+d_{i}^{-}} \quad 0 \leq C_{i} \leq 1, \quad i=1,2, \ldots, m
$$

(7) Alternative ranking in accordance with the relative similarity degree $C_{i}$.

\subsection{Improved TOPSIS model}

Generally, the above described traditional TOPSIS model can be solved by means of the Lagrangian function. In practical application, some problems may occur if the index weights get zero values. Under such situation, the solution process cannot be realized. Some improvements should, therefore, be made to the traditional TOPSIS model.

\subsubsection{Index standardization}

In the translation process from the original decision matrix $A=\left(a_{i j}\right)_{m \times n}$ to the dimensionless matrix $R=\left(r_{i j}\right)_{m \times n}$, $r_{i j}=\left[r_{i j}^{\mathrm{L}}, r_{i j}^{\mathrm{U}}\right]$, a new term 'base point' is introduced which will be determined as follows:

For the efficiency index, $x_{j}\left(x_{j} \neq 0, j=1,2,3, \ldots, n\right)$ are set as the 'base points' for the comparison process according to Eq. (3),

$x_{j}=\max _{i=1}\left\{\left|a_{i j}^{\mathrm{L}}\right|,\left|a_{i j}^{\mathrm{U}}\right|\right\}$.

For the cost index, $y_{j}\left(y_{j} \neq 0, j=1,2,3, \ldots, n\right)$ are set as the 'base points' for comparison process according to Eq. (4),

$y_{j}=\min _{i=1}^{m}\left\{\left|a_{i j}^{\mathrm{L}}\right|,\left|a_{i j}^{\mathrm{U}}\right|\right\}$.

The dimensionless process can be undertaken for both the efficiency index and cost index respectively according to Eqs. (5) and (6),

$r_{i j}^{\mathrm{L}}=\frac{a_{i j}^{\mathrm{L}}}{x_{j}}, \quad r_{i j}^{\mathrm{U}}=\frac{a_{i j}^{\mathrm{U}}}{x_{j}}$

$r_{i j}^{\mathrm{L}}=\min \left(\frac{y_{j}}{a_{i j}^{\mathrm{L}}}, \frac{y_{j}}{a_{i j}^{\mathrm{U}}}\right), \quad r_{i j}^{\mathrm{U}}=\max \left(\frac{y_{j}}{a_{i j}^{\mathrm{L}}}, \frac{y_{j}}{a_{i j}^{\mathrm{U}}}\right)$

In the practical decision process, both the efficiency index and cost index may occur in the index set. In such a situation, all the cost index would be turned into their reciprocals according to Eq. (7),

$r_{i j}=\frac{\left(x_{i j}\right)^{-1}}{\max _{1 \leq i \leq m}\left(x_{i j}\right)^{-1}}=\frac{\min _{1 \leq i \leq m}\left(x_{i j}\right)}{\left(x_{i j}\right)}=\frac{x_{i j}^{\min }}{x_{i j}}$,

where $x_{i j}^{\min }=\min _{1 \leq i \leq m}\left(x_{i j}\right) \quad(1 \leq j \leq n)$. 
And then, the whole index could be considered as 'efficiency index'.

\subsubsection{Establishing the weighted normalized decision matrix}

According to the information obtained from the first step, the weighted normalized decision matrix can be established as follow,

$B=\left(b_{i j}\right)_{m \times n}, \quad b_{i j}=\left[w_{j}^{\mathrm{L}} r_{i j}^{\mathrm{L}}, w_{j}^{\mathrm{U}} r_{i j}^{\mathrm{U}}\right]$.

\subsubsection{Setting the ideal model}

Because the interval numbers are composed of upper- and lower-limits, we do not need both positive and negative modes together. In order to avoid redundant calculations in solving the decision problem, the positive mode and the negative mode are combined into one ideal mode as follows:

$S^{*}=\left\{s_{1}^{*}, s_{2}^{*}, \ldots, s_{j}^{*}\right\} \quad(j=1,2,3, \ldots, n)$,

where, $s_{j}^{*}=\left[s_{j}^{\mathrm{L}}, s_{j}^{\mathrm{U}}\right]$,

$s_{j}^{\mathrm{L}}=\max _{i} b_{i j}^{\mathrm{L}}=\max _{i} w_{j}^{\mathrm{L}} r_{i j}^{\mathrm{L}}, \quad s_{j}^{\mathrm{U}}=\max _{i} b_{i j}^{\mathrm{U}}=\max _{i} w_{j}^{\mathrm{U}} r_{i j}^{\mathrm{U}}$

Let

$\left(r_{j}^{*}\right)^{\mathrm{L}}=\max _{i} r_{i j}^{\mathrm{L}}, \quad\left(r_{j}^{*}\right)^{\mathrm{U}}=\max _{i} r_{i j}^{\mathrm{U}}$

and then, Eq. (8) can be expressed as follows:

$s_{j}^{\mathrm{L}}=w_{j}^{\mathrm{L}}\left(r_{j}^{*}\right)^{\mathrm{L}}, \quad s_{j}^{\mathrm{U}}=w_{j}^{\mathrm{U}}\left(r_{j}^{*}\right)^{\mathrm{U}}$.

\subsubsection{Calculating the geometric distance and determining the interval weight}

The Euclidean geometric distance principle is applied here as in the traditional TOPSIS model. The distance of alternative $S_{i}$ to the ideal mode $S^{*}$ is calculated according to the formula (11),

$$
\begin{aligned}
d_{i} & =\sqrt{\sum_{j=1}^{n}\left(b_{i j}-s_{j}^{*}\right)^{2}} \\
& =\sqrt{\sum_{j=1}^{n}\left\{\left[w_{j}^{\mathrm{L}} r_{i j}^{\mathrm{L}}-w_{j}^{\mathrm{L}}\left(r_{j}^{*}\right)^{\mathrm{L}}\right]^{2}+\left[w_{j}^{\mathrm{U}} r_{i j}^{\mathrm{U}}-w_{j}^{\mathrm{U}}\left(r_{j}^{*}\right)^{\mathrm{U}}\right]^{2}\right\} .}
\end{aligned}
$$

The smaller the geometric distance, the better the alternative. According to this principle, an optimization model can be established for determining the index weights as follows:

$\min \left[\sum_{i=1}^{m} d_{i}(w)\right]=\min \left[\sum_{i=1}^{m}\left(\sqrt{\sum_{j=1}^{n}\left(b_{i j}-s_{j}^{*}\right)^{2}}\right)\right]$

s.t. $\left\{\begin{array}{l}\sum_{j=1}^{n} w_{j}^{\mathrm{L}} \leq 1 \\ \sum_{j=1}^{n} w_{j}^{\mathrm{U}} \geq 1 \\ w_{j}>0, \quad j=1,2, \ldots, n\end{array}\right.$.

The model (12) can be turned into its equivalent form [see model (13)].

$$
\begin{aligned}
\min \left[d_{i}^{2}(w)\right]= & \min \left[\sum_{i=1}^{m}\left(\sum_{j=1}^{n}\left(b_{i j}-s_{j}^{*}\right)^{2}\right)\right] \\
= & \min \left[\sum _ { i = 1 } ^ { m } \left(\sum _ { j = 1 } ^ { n } \left\{\left[w_{j}^{\mathrm{L}} r_{i j}^{\mathrm{L}}-w_{j}^{\mathrm{L}}\left(r_{j}^{*}\right)^{\mathrm{L}}\right]^{2}\right.\right.\right. \\
& \left.\left.\left.+\left[w_{j}^{\mathrm{U}} r_{i j}^{\mathrm{U}}-w_{j}^{\mathrm{U}}\left(r_{j}^{*}\right)^{\mathrm{U}}\right]^{2}\right\}\right)\right]
\end{aligned}
$$

s.t. $\left\{\begin{array}{l}\sum_{j=1}^{n} w_{j}^{\mathrm{L}} \leq 1 \\ \sum_{j=1}^{n} w_{j}^{\mathrm{U}} \geq 1 \\ w_{j}>0, \quad j=1,2, \ldots, n\end{array}\right.$

It can be seen that this is a nonlinear optimization model. The Lagrangian function (14) can be introduced for solving the model.

$$
\begin{aligned}
L(w, \lambda)= & \sum_{i=1}^{m}\left(\sum_{j=1}^{n}\left[\left[r_{i j}^{\mathrm{L}}-\left(r_{j}^{*}\right)^{\mathrm{L}}\right]^{2}+\left[r_{i j}^{\mathrm{U}}-\left(r_{j}^{*}\right)^{\mathrm{U}}\right]^{2}\right]\left[w_{j}\right]^{2}\right) \\
& +2 \lambda\left(\sum_{j=1}^{n}\left[w_{j}\right]-[1,1]\right)
\end{aligned}
$$

The partial derivative equations can be then easily obtained as follows:

$\left\{\begin{array}{l}\frac{\partial L}{\partial\left[w_{j}\right]}=2\left[w_{j}\right] \sum_{i=1}^{m}\left[\left(r_{i j}-r_{j}^{*}\right)^{2}\right]+2[\lambda, \lambda]=0 \\ \frac{\partial L}{\partial \lambda}=\sum_{j=1}^{n}\left[w_{j}\right]-[1,1]=0\end{array}\right.$.

By solving the model, the following index weight vector can be obtained,

$W=\left(w_{1}, w_{2}, \ldots, w_{n}\right)^{T}, \quad$ where,$w_{j}=\left[w_{j}^{\mathrm{L}}, w_{j}^{\mathrm{U}}\right]$ 
4.3.5 Calculating the comprehensive evaluation value of each alternative

By applying the above obtained index weights, the comprehensive evaluation value of each alternative can be calculated as follows:

$Z_{i}\left(w_{j}\right)=\left[z_{i}^{\mathrm{L}}, z_{i}^{\mathrm{U}}\right],(i=1,2,3, \ldots, m)$,

where

$z_{i}^{\mathrm{L}}=\sum_{j=1}^{n} w_{j}^{\mathrm{L}} r_{i j}^{\mathrm{L}}, \quad z_{i}^{\mathrm{U}}=\sum_{j=1}^{n} w_{j}^{\mathrm{U}} r_{i j}^{\mathrm{U}}$

\subsubsection{Alternative ranking}

For an interval MADM problem, the optimal alternative can be found by means of comparing the comprehensive evaluation values obtained from a series of calculations described in step (5). Instead of using the similarity degree principle in the traditional TOPSIS model, the possibility degree principle is used for the alternative ranking in this paper. The ranking method based on the possibility degree is a popular method of dealing with interval number models. The 'possibility degree' is defined as follows.

Suppose that we have two interval numbers, $a$ and $b$, ( $a=\left[a^{\mathrm{L}}, a^{\mathrm{U}}\right]$ and $b=\left[b^{\mathrm{L}}, b^{\mathrm{U}}\right]$ ). The lengths of interval numbers are written as $l(a)=a^{\mathrm{U}}-a^{\mathrm{L}}$ and $l(b)=b^{\mathrm{U}}-b^{\mathrm{L}}$. The possibility degree is calculated as follows:

$P(a \geq b)=\min \left\{\max \left(\frac{a^{\mathrm{U}}-b^{\mathrm{L}}}{l(a)+l(b)}, 0\right), 1\right\}$

$P(a \geq b)=\max \left\{1-\max \left(\frac{b^{\mathrm{U}}-a^{\mathrm{L}}}{l(a)+l(b)}, 0\right), 0\right\}$

The ranking and comparison among more than two interval numbers will be more complicated. Under such situation, we should, firstly, carry out the comparison between each other. A possibility degree matrix $P$ will be, then, obtained by arranging all the results from the comparisons (ref. to formula (19)).

$P=\left(\begin{array}{cccc}0.5 & p_{12} & \cdots & p_{1 n} \\ p_{21} & 0.5 & \cdots & p_{2 n} \\ \vdots & \vdots & \vdots & \vdots \\ p_{n 1} & p_{n 2} & \cdots & 0.5\end{array}\right), \quad$ where $p_{i j}=P\left(S_{i}>S_{j}\right)$

Based on the possibility degree matrix, the ranking value of an alternative is calculated according to formula (20). All the alternatives can be ranked by comparing their ranking values.

$$
v_{i}=\frac{\sum_{j=1}^{m} p_{i j}+\frac{n}{2}-1}{n(n-1)}, \quad(i=1,2, \ldots, n)
$$

\section{Application}

An oil company had an investment opportunity for development of oil and gas blocks in the Middle East. The company could select some promising blocks from the 13 oil and gas blocks in 8 different countries in the Middle East. The MADM theory and the improved TOPSIS model described above were to be applied for supporting the company's decision.

These 13 blocks (projects)) would be taken as the alternatives and formed the alternative set. $S$,

$S_{i}=\{$ Ash Sham block, Oude block, Gbeibe block, Abu Al Bukhoosh block, Bunduq block, Darquain block, Masjid-e-Suleiman block, Majnoon block, Rumaila block, Onshore Partitioned Zone block, Block 6 block, Malik block, Mukhaizna block\}. More details about the alternatives are shown in Table 3.

The interval weights of the index and the comprehensive evaluation values of the blocks were obtained using the improved TOPSIS model, with the results shown in Tables 4 and 5. As we can see from Table 4 , no index has zero-weight, which proves the effectiveness of the model improvement described above in this paper.

Based on the comprehensive evaluation values above, the possibility degrees were calculated using Eqs. (17) and (18). The possibility degree matrix was obtained through arranging all the results from the comparisons between every alternative. According to Eqs. (20), the ranking values of all the alternatives were calculated, and on these bases the project ranking was given. The result is shown in Table 6 .

According to the results shown in Table 6, the best five projects (blocks) are Rumaila in Iraq, Abu Al Bukhoosh in United Arab Emirates, Onshore Partitioned Zone in Saudi Arabia, Gbeibe in Syria and Majnoon in Iraq, with ranking values $0.07970,0.07966,0.07948,0.07924$ and 0.07889 respectively. The worst two projects (blocks) are Malik block in Yemen and Mukhaizna block in Oman.

As suggestions to the oil company, Iraq Rumaila project (block) should be chosen first, while Malik block in Yemen and Mukhaizna block in Oman could not be considered. Taking the geopolitical and other related factors into account, the company should pay more attention to the blocks in Iran, Saudi Arabia and the United Arab Emirates. In consideration of the situation in Iraq and the instability in Syria, the company might give up the blocks in these two countries, even though these blocks have better ranking values. If decision makers 
Table 3 The information of projects (blocks)

\begin{tabular}{llllll}
\hline No. & Name & Country & No. & Name & Country \\
\hline 1 & Ash Sham & Syria & 8 & Majnoon & Iraq \\
2 & Oude & Syria & 9 & Rumaila & Iraq \\
3 & Gbeibe & Syria & 10 & Block 6 & Qatar \\
4 & Abu Al Bukhoosh & UAE & 11 & Malik & Yemen \\
5 & Bunduq & UAE & 12 & Mukhaizna & Oman \\
6 & Darquain & Iran & 13 & Onshore Partitioned Zone & Saudi Arabia \\
7 & Masjid-e-Suleiman & Iran & & & \\
\hline
\end{tabular}

Table 4 The index weights

\begin{tabular}{|c|c|c|c|c|c|c|c|}
\hline Index & & $w_{j}^{\mathrm{L}}$ & $w_{j}^{\mathrm{U}}$ & Index & & $w_{j}^{\mathrm{L}}$ & $w_{j}^{\mathrm{U}}$ \\
\hline Reserves & $w_{1}$ & 0.0032 & 0.0088 & Buried depth & $w_{11}$ & 0.1038 & 0.1186 \\
\hline Reserve abundance & $w_{2}$ & 0.0041 & 0.011 & Cover lithology & $w_{12}$ & 0.0834 & 0.1024 \\
\hline Hydrocarbon source rock thickness & $w_{3}$ & 0.0204 & 0.0243 & Cover layer thickness & $w_{13}$ & 0.0291 & 0.0743 \\
\hline Lithology & $w_{4}$ & 0.0474 & 0.0703 & Crude oil density & $w_{14}$ & 0.0127 & 0.0686 \\
\hline Organic carbon content & $w_{5}$ & 0.1087 & 0.1226 & Peak production & $w_{15}$ & 0.0034 & 0.0094 \\
\hline Hydrocarbon generation peak time & $w_{6}$ & 0.0201 & 0.0214 & Well depth & $w_{16}$ & 0.01 & 0.017 \\
\hline Trap type & $w_{7}$ & 0.0558 & 0.1124 & Expected investment & $w_{17}$ & 0.004 & 0.0104 \\
\hline Reservoir thickness & $w_{8}$ & 0.0207 & 0.0282 & The total cost & $w_{18}$ & 0.0042 & 0.0112 \\
\hline Porosity & $w_{9}$ & 0.1175 & 0.1499 & Expected NPV & $w_{19}$ & 0.0054 & 0.0134 \\
\hline Permeability & $w_{10}$ & 0.1137 & 0.1281 & Expected IRR & $w_{20}$ & 0.0089 & 0.0211 \\
\hline
\end{tabular}

Table 5 The comprehensive evaluation values of the alternatives

\begin{tabular}{llllll}
\hline No. & Name & Value & No. & Name & Value \\
\hline 1 & Ash Sham & {$[0.5470,0.9803]$} & 8 & Majnoon & {$[0.5311,1.0015]$} \\
2 & Oude & {$[0.5084,0.9331]$} & 9 & Rumaila & {$[0.5656,1.0771]$} \\
3 & Gbeibe & {$[0.4984,0.9104]$} & 10 & Block 6 & {$[0.5289,0.9533]$} \\
4 & Abu Al Bukhoosh & {$[0.5028,0.9093]$} & 11 & Malik & {$[0.4922,0.9573]$} \\
5 & Bunduq & {$[0.4636,0.8964]$} & 12 & Mukhaizna & {$[0.4412,0.9270]$} \\
6 & Darquain & {$[0.5340,0.9703]$} & 13 & Onshore Partitioned Zone & {$[0.5128,1.0171]$} \\
7 & Masjid-e-Suleiman & {$[0.5660,1.0602]$} & & & \\
\hline
\end{tabular}

prefer some economic index (such as NPV, etc.), they can calculate the NPVs (expressed in interval numbers) for every block separately according to the interval index weights in Table 4. They can build the possibility degree matrix based on the NPV comparisons. so as to get the final ranking results.

\section{Summary and conclusions}

Analysis was made on the important attributes (index) to which more attention can be given in overseas oil-gas project selection. The relationships among factors affecting the economic result were described. A new TOPSIS model was presented based on improving the traditional one so as to meet the special requirements from overseas oil and gas project selection. This model was applied in the ranking and selection decision of the oil and gas blocks (projects) in the Middle East. Some innovative work and conclusions are summarized as follows.

\subsection{Improvements in theory and method aspect}

(a) The index weights are expressed in interval number form instead of in point data form as in the traditional models. Because of some weakness in knowledge and experience, it is very difficult to give a relatively accurate estimate to the weights of attribute or index in the evaluation of overseas oil and gas projects. The interval number is the most suitable form for expressing such uncertainty. The index 
Table 6 The result of ranking

\begin{tabular}{llllr}
\hline No. & Name & Country & Rank value & Ranking \\
\hline 1 & Ash Sham & Syria & 0.07764 & 10 \\
2 & Oude & Syria & 0.07790 & 8 \\
3 & Gbeibe & Syria & 0.07924 & 4 \\
4 & Abu Al Bukhoosh & UAE & 0.07966 & 2 \\
5 & Bunduq & UAE & 0.07732 & 11 \\
6 & Darquain & Iran & 0.07807 & 7 \\
7 & Masjid-e-Suleiman & Iran & 0.07814 & 6 \\
8 & Majnoon & Iraq & 0.07889 & 5 \\
9 & Rumaila & Iraq & 0.07970 & 1 \\
10 & Onshore Partitioned Zone & Saudi Arabia & 0.07948 & 3 \\
11 & Block 6 & Qatar & 0.07784 & 9 \\
12 & Malik & Yemen & 0.07646 & 12 \\
13 & Mukhaizna & Oman & 0.07424 & 13 \\
\hline
\end{tabular}

weights expressed in interval number form are, therefore, introduced in this paper.

(b) In order to avoid redundant calculations in solving the decision problem, the positive mode and the negative mode are combined into one ideal mode, as the interval numbers are composed of upper- and lower-limits. The closer an alternative is to the ideal mode, the better it is. An alternative will be considered as better in view of the index, when the standardized interval value of the efficiency index is closer to the interval [1,1]. With the cost index, an alternative will be considered as better in view of the index, when the standardized interval value of the cost index is closer to the interval $[0,0]$.

(c) Instead of using the similarity degree principle, the possibility degree principle is applied in the comparison of the comprehensive evaluation values of the alternatives. The alternative ranking is conducted based on the possibility degree matrix.

\subsection{Improvements in application aspect}

(a) The application of the MADM theory is expanded from reserve evaluation to the total project economic evaluation in the oil and gas industry.

(b) The introduction of interval numbers into the evaluation and ranking of the overseas oil and gas projects can lead to more reasonable decisions, because interval data can much better accommodate the incompleteness of geological information and the uncertainty of the economic results.

(c) A new tool, the improved TOPSIS model, is provided for the evaluation of overseas oil and gas projects. The users can do the project evaluation based on the comprehensive values as in the model application in the paper. They can also only select their preferred index in the project evaluation and ranking.

Acknowledgments This work was supported by the National Social Science Foundation key projects (13\&ZD159, 11\&ZD164).

Open Access This article is distributed under the terms of the Creative Commons Attribution License which permits any use, distribution, and reproduction in any medium, provided the original author(s) and the source are credited.

\section{References}

Albayrak E. Using analytic hierarchy process (AHP) to improve human performance. J Intell Manuf. 2004;15:491-503.

Dağdeviren M. Decision making in equipment selection: an integrated approach with AHP and Prometree. J Intell Manuf. 2008;19(4): 397-06.

Fan ZP, Ma J, Zhang Q. An approach to multiple attribute decision making based on Fuzzy preference information on alternatives. Fuzzy Sets Syst. 2002;131:101-6.

Herrera F, Herrera E, Martinez L, et al. Managing non-homogeneous information in group decision making. Eur J Oper Res. 2005; 166(1):115-32.

Hladik M. Solution set characterization of linear interval systems with a specific dependence structure. Reliable Comput. 2007;13(4): 361-74.

Hou B, Gui ZX. Application of multi-attribute and neural network method to hydrocarbon reservoir prediction. Lithol Reserv. 2010;3(22):118-21.

Janic M. Multicriteria evaluation of high-speed rail, transrapid maglev, and air passenger transport in Europe. Transp Plan Technol. 2003;26(6):491-512.

Kong F. On fuzzy multi-attribute decision making theory and its applications in technical economic analysis. Thesis. North China Electric Power University; 2005.

Li DX. The application of fuzzy multi-attribute decision making method to mineral resource exploitation. Thesis. Wuhan University of Technology; 2004. 
Liu XF. Research on investment project economic appraisal based on multiple attribute decision-making. Thesis. TianJin University; 2007.

Liu YA. Evaluation of undeveloped oil \& gas reserves based on multi-attribute decision-making. Stat Inf Forum. 2010;9(25): 63-8.
Srdjevic B, Medeiros YDP, Faria AS. An objective multi-criteria evaluation of water management scenarios. Water Resour Manag. 2004;18:35-54.

Wang Z, Zhang SN, Kuang JC. Risk decision-making model for oil \& gas exploration based on dynamic MAUT. China Min Mag. 2010;19(1):110-3. 